Revista Destaques Acadêmicos, Lajeado, v. 9, n. 4, 2017. ISSN 2176-3070 DOI: http://dx.doi.org/10.22410/issn.2176-3070.v9i4a2017.1676 www.univates.br/revistas

\title{
DESEMPENHO TÉRMICO E EFICIÊNCIA ENERGÉTICA: ESTUDO DE CASO
}

\author{
Aline Patrícia Hunemeier ${ }^{1}$, Amanda Martini Spezia ${ }^{2}$
}

Resumo: Este trabalho tem por objetivo avaliar as condições de desempenho térmico de três ambientes de uma residência de $131,61 \mathrm{~m}^{2}$ no município de Estrela/RS. Para conhecer o desempenho térmico foi calculado o fluxo térmico de cada ambiente, através de uma série de fórmulas apresentadas, somando o calor transmitido por equipamentos, iluminação e pessoas que frequentam o ambiente. Dimensionou-se os equipamentos de ar condicionado e foi feita uma simulação do gasto de kW.h e da conta mensal de energia. Tendo em vista o grande gasto energético, foi apresentada uma solução com a adoção de novos conjuntos de materiais.

Palavras-chave: Desempenho térmico. Eficiência energética. Economia de energia.

\section{INTRODUÇÃO}

Através do progresso de tecnologias, a concepção de projetos arquitetônicos passou a desprezar o clima externo, desconsiderando estratégias de desempenho térmico e eficiência energética, gerando um microclima interno. Para esse microclima interno ser alcançado, a edificação passou a contar com equipamentos de aquecimento, resfriamento e ventilação artificiais que consomem enormes quantidades de energia. Dessa forma, as edificações se tornaram totalmente dependentes do consumo de energia elétrica.

No entanto, nas últimas décadas as questões relacionadas à sustentabilidade e o desenvolvimento sustentável ganhou mais destaque quanto às necessidades de modificar a forma com que a sociedade consome. Sendo assim, o setor da construção civil, por ser um dos que mais causa impactos negativos ao ambiente, começou a passar por transformações. Aliado a esse cenário, o aumento do consumo de energia elétrica, ocasionado pelo aumento da população e da industrialização do país, causou racionamentos de energia em 2001. Percebeu-se que a energia não é infinita, e tendo em vista que a relação

1 Graduanda em Engenharia Civil. Universidade do Vale do Taquari UNIVATES.

2 Graduanda em Engenharia Civil. Universidade do Vale do Taquari UNIVATES. 
entre o consumo de energia e o envoltório da edificação é inegável (FAVOINO, JIN E OVEREND, 2017), medidas e incentivos para redução do consumo de energia foram estabelecidas. Algumas normas foram criadas para definir, entre outras condições, o desempenho térmico mínimo de uma edificação, como por exemplo, a NBR 15575-1 (ABNT, 2013), que está em vigor atualmente.

De acordo com Peralta (2006), o desempenho térmico da edificação sofre influência de fontes internas e externas. A respeito das fontes externas, segundo Givoni (1998), os materiais usados na construção das edificações influenciam diretamente entre a relação da temperatura externa e condições de radiação com a temperatura interna em edificações não climatizadas. Os elementos que compõe fachadas e coberturas são os que mais têm influência como fonte externa, e sendo assim, no consumo de energia. Dessa forma, é necessário mensurar grandezas como capacidade térmica e transmitância térmica desses elementos. Na porção da carga interna, é necessário determinar fontes internas de calor, como equipamentos, pessoas que utilizam o ambiente e iluminação do local. Tendo o estudo dessas variáveis, muitas vezes é possível sugerir outra combinação de materiais e aparelhos utilizados, para um melhor desempenho térmico da edificação.

\section{OBJETIVOS}

O intuito desse artigo é analisar o desempenho térmico de três ambientes de uma residência localizada no município de Estrela/RS, e encontrar uma estratégia para a melhora no desempenho térmico do local, utilizando um novo conjunto de materiais a serem elaborados.

\subsection{Delimitação do estudo}

Este estudo realizará uma análise do desempenho térmico de três ambientes de uma residência, sendo estes caracterizados por uma sala de jantar com área de 20,955 m²; e dois dormitórios com 10,80 $\mathrm{m}^{2}$ cada um. Para o cálculo serão considerados apenas as paredes externas e a cobertura destes cômodos, sem avaliar os banheiros e demais ambientes do local. Desta forma, as faces analisadas na sala de jantar são as voltadas para o norte e oeste; na suíte 1 as faces norte e leste e na suíte 2 apenas a sul.

\section{MÉTODO}

\subsection{Aspectos Gerais}

O método utilizado para a realização do trabalho constitui-se de seis partes, explicadas a seguir:

- Analisar o desempenho térmico da residência atual conforme projeto; 
- Verificar se há necessidade/possibilidade de modificar algum material construtivo para melhorar a eficiência da residência;

- Definir os materiais a serem substituídos;

- Reanalisar o desempenho térmico da residência com as modificações de materiais realizadas;

- Verificar a melhora na eficiência, comparando os dois casos;

- Dimensionamento do ar condicionado ideal para cada ambiente.

\subsection{Edificação Avaliada}

A edificação avaliada é uma residência no município de Estrela/RS, com área total equivalente a 131,61 m², como mostra a Figura 1.

Figura 1 - Planta baixa da residência avaliada

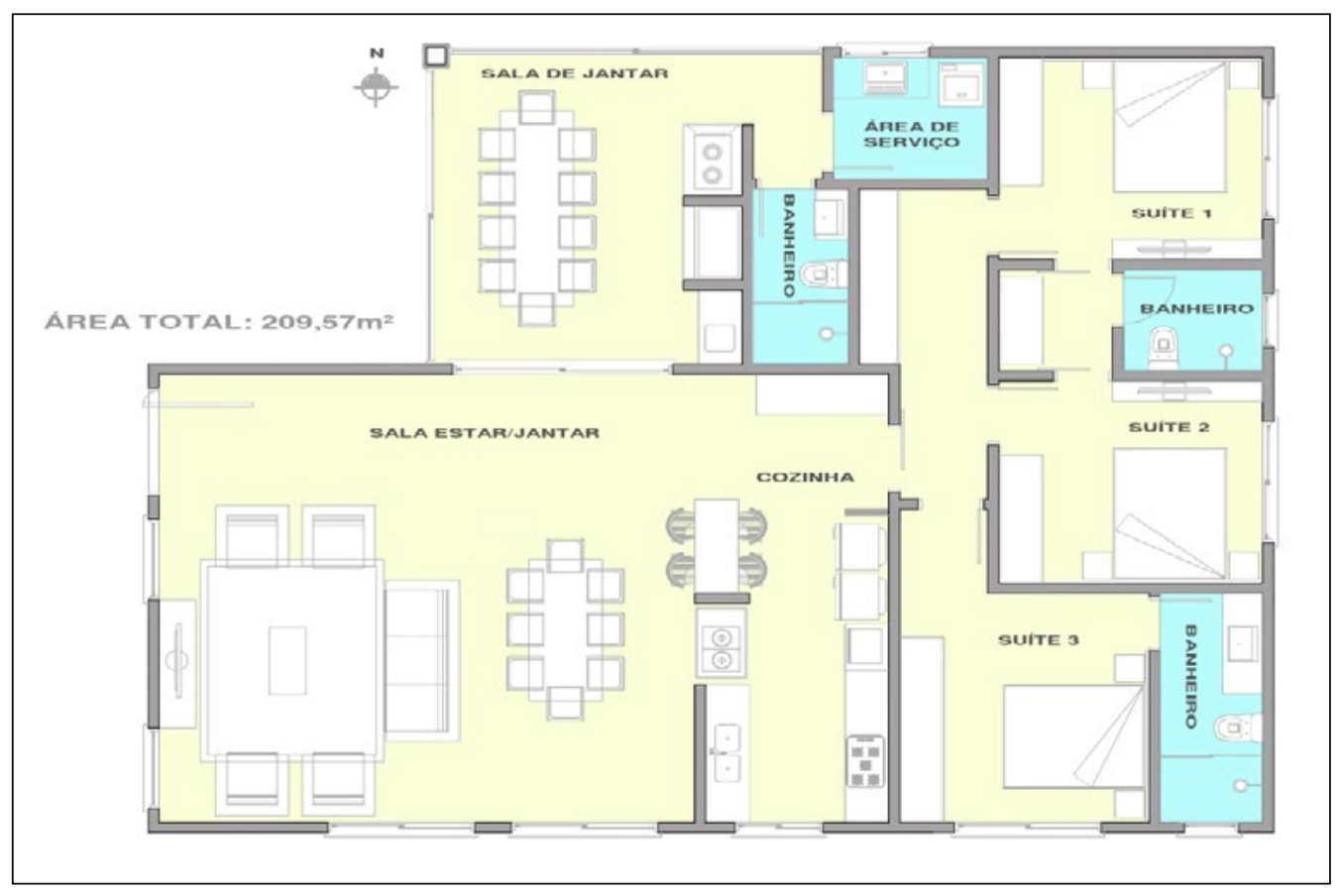

Fonte: das autoras

\subsection{Composições construtivas dos ambientes}

A composição construtiva da residência analisada, conforme projeto, é com modulação de bloco de concreto em espessura de $14 \mathrm{~cm}$, conforme apresentado na Figura 2. A parede é constituída de bloco vazado até a altura de 2,6 m, observado na Figura 3. E após conta com uma camada de bloco de 
concreto maciço, de altura de $19 \mathrm{~cm}$, responsável por aumentar a resistência da estrutura. Totalizando assim, uma altura de paredes de 2,8 $\mathrm{m}$. Ele possui reboco interno e externo de $2 \mathrm{~cm}$ cada, e pintura na cor amarela.

Figura 2 - representação dos blocos de concreto utilizados

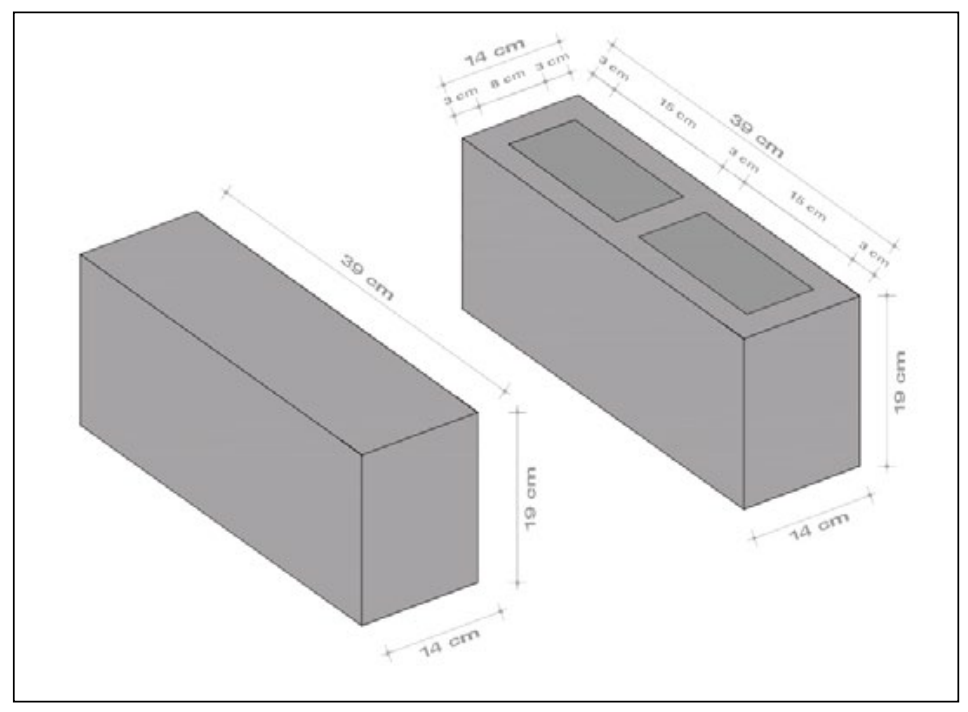

Fonte: das autoras

Figura 3 - Modulação da parede com os blocos vazados e maciços

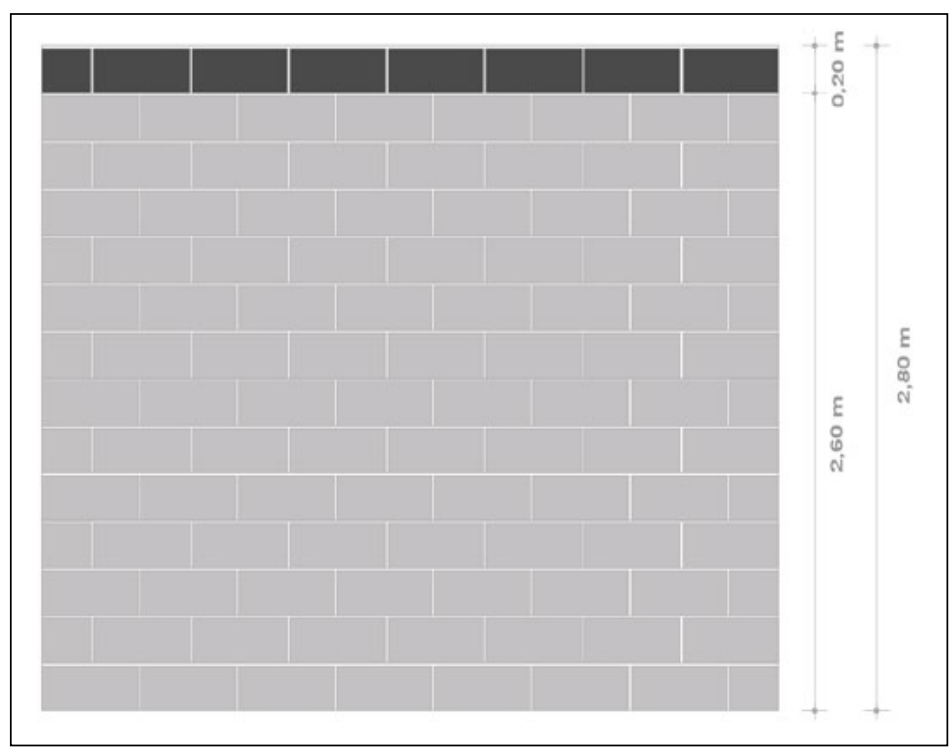

Fonte: das autoras 
Os três ambientes avaliados são compostos por duas suítes e uma sala de jantar. As suítes são construídas em bloco de concreto conforme descrito anteriormente. Já o fechamento externo da sala de jantar é de vidro comum de $3 \mathrm{~mm}$, contando com um pilar entre a posição norte e oeste, que possui $19 \mathrm{~cm}$ de concreto, mais $2 \mathrm{~cm}$ em cada lado de reboco. Todos os ambientes contam com a camada de 19 $\mathrm{cm}$ de bloco maciço, representando assim a viga da edificação.

A cobertura é constituída por uma laje maciça de $10 \mathrm{~cm}$, com reboco interno de $2 \mathrm{~cm}$ e uma câmara de ar acima da laje com espessura superior a 5 $\mathrm{cm}$, finalizando com uma telha de barro de $1 \mathrm{~cm}$.

Figura 4 - Planta baixa da sala de jantar com suas respectivas dimensões

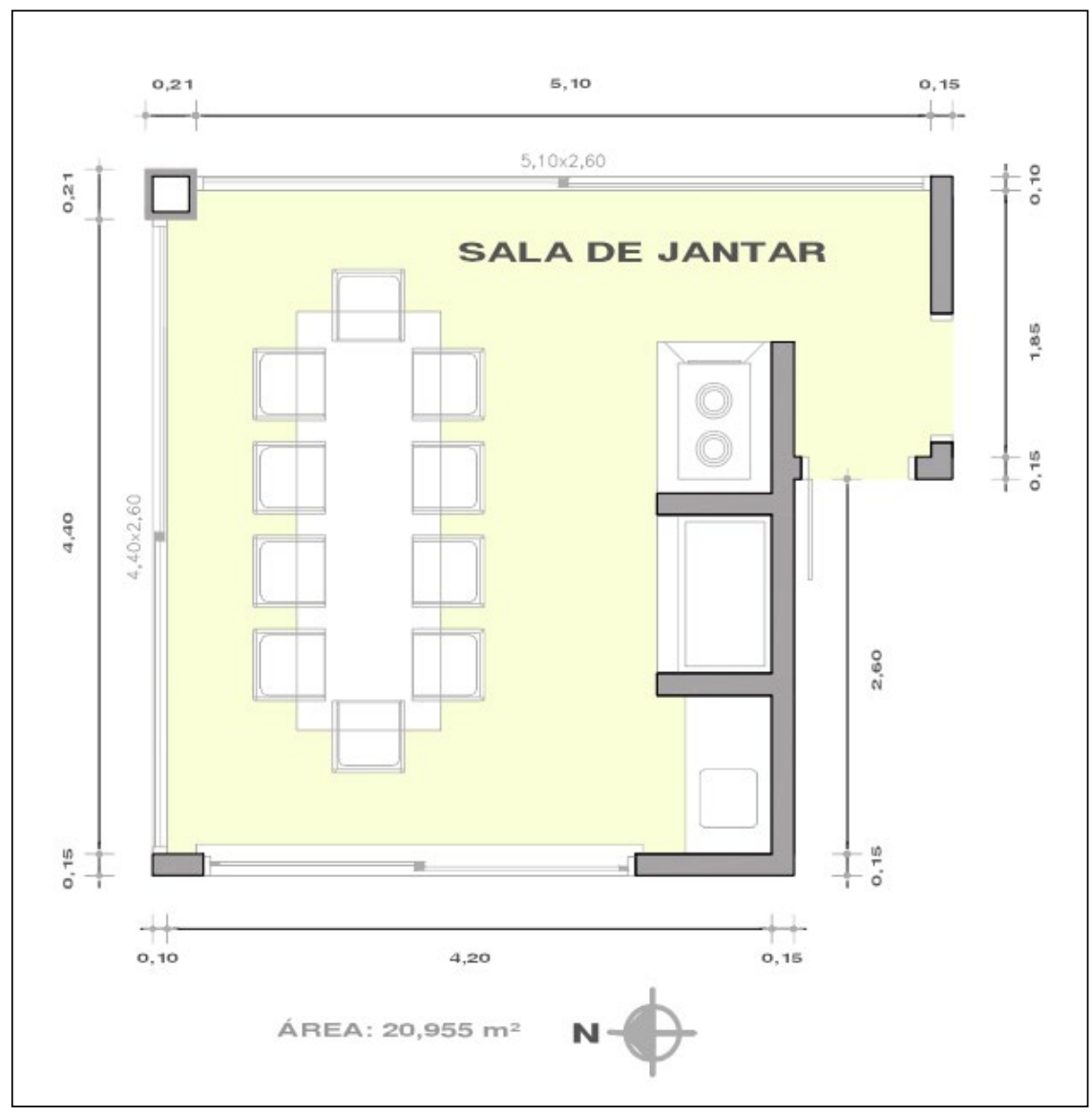

Fonte: das autoras. 
Figura 5 - Planta baixa das suítes com suas respectivas dimensões

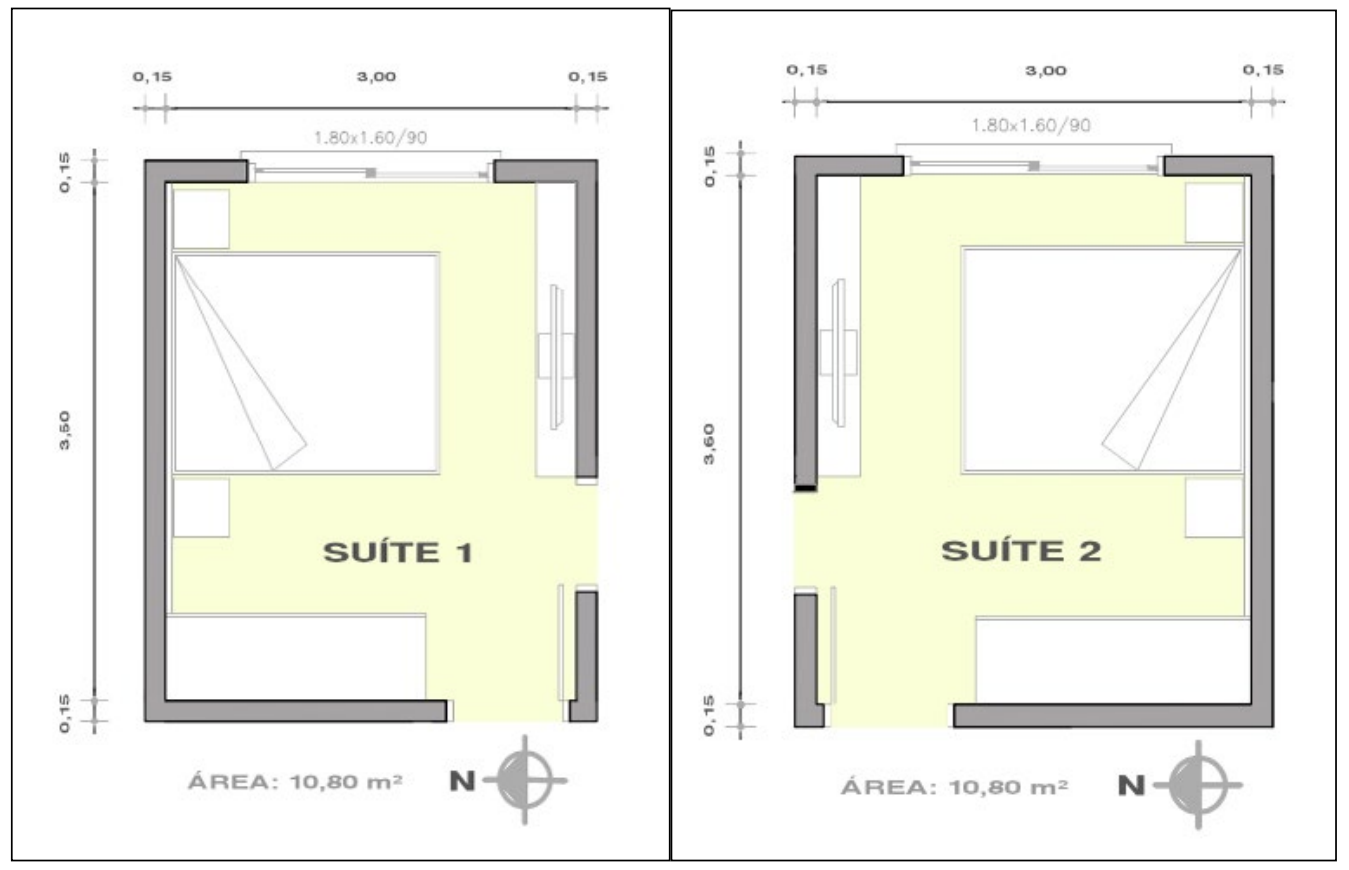

Fonte: das autoras.

\subsection{Cálculo Fechamentos Opacos}

Para encontrar o desempenho térmico destes ambientes, as seguintes fórmulas foram resolvidas:

Em fechamentos opacos, como paredes, calcula-se:

Resistência Térmica das Superfícies (Rt)

$$
\begin{aligned}
& R t=\sum\left(\frac{\text { e camadas }}{\lambda \text { camadas }}+\text { Rar }\right) \\
& \text { e }=\text { espessura da camadas analisada } \\
& \lambda=\text { condutividade térmica do material }
\end{aligned}
$$

Rar $=$ resistência da camada de ar(se possuir)

As paredes são compostas por blocos de concreto vazados e maciços, com espessuras apresentadas na Figura 2, mais reboco interno e externo, de $2 \mathrm{~cm}$ de espessura cada. $\mathrm{O}$ pilar e a cobertura têm suas espessuras apresentadas anteriormente. 
A condutividade térmica do concreto é $1,75(\mathrm{~W} /(\mathrm{m} . \mathrm{K}))$, da argamassa é $1,15(\mathrm{~W} /(\mathrm{m} . \mathrm{K}))$ e da telha de barro é $0,7(\mathrm{~W} /(\mathrm{m} . \mathrm{K}))$, conforme a Tabela B.3 do Projeto 02:135.07-002 (ABNT, 2003). A resistência da camada de ar do bloco vazado é 0,17 e da camada de ar da cobertura é 0,61 , de acordo com a Tabela B.3 do Projeto 02:135.07-002 (ABNT, 2003).

\section{Resistência Térmica Total (RT)}

$R T=R s i+R t+R s e$

Rsi $=$ resistência da superfície exterior

Rse $=$ resistência da superfície interior

As resistências das superfícies são retiradas da Tabela A.1 do Projeto 02:135.07-002 (ABNT, 2003), sendo Rsi 0,13 $\left(\mathrm{m}^{2} . \mathrm{K}\right) / \mathrm{W}$ e Rse $0,04\left(\mathrm{~m}^{2} . \mathrm{K}\right) / \mathrm{W}$.

\section{Transmitância Térmica (U)}

$$
U=\frac{1}{R T}
$$

A Tabela 1 apresenta os valores de Rt, RT e U para as 3 composições do projeto.

Tabela 1 - Valores de Rt, RT e U

\begin{tabular}{l|l|l|l}
\hline & $\mathbf{R t}\left(\mathbf{m}^{2} \cdot \mathbf{K}\right) / \mathbf{W}$ & $\mathbf{R T}\left(\mathbf{m}^{\mathbf{2}} \cdot \mathbf{K}\right) / \mathbf{W}$ & $\left.\mathbf{U ~ W} / \mathbf{m}^{\mathbf{2}} \cdot \mathbf{k}\right)$ \\
\hline Pilar & 0,178 & 0,348 & 2,877 \\
\hline Parede maciça (viga) & 0,115 & 0,285 & 3,511 \\
\hline Parede vazada & 0,239 & 0,409 & 2,358 \\
\hline Cobertura & 0,699 & 0,909 & 1,100 \\
\hline
\end{tabular}

Fonte: das autoras.

\section{Fluxo Térmico (q)}

$$
\begin{aligned}
& q=\alpha{ }^{*} I^{*} R s e+t e-t i \\
& \alpha=\text { absortividade da superfície externa do fechamento } \\
& I=\text { radiação solar conforme latitude } \\
& \text { Rse = resistência da superfície externa } \\
& \text { te }=\text { temperatura externa } \\
& \text { ti }=\text { temperatura interna }
\end{aligned}
$$


A absortividade da superfície externa do fechamento, pintura amarela, pode ser encontrada na Tabela B.3 do Projeto 02:135.07-002 (ABNT, 2003) e é igual a 0,3 ; e da telha cerâmica é igual a 0,9 .

O valor da radiação solar é considerado o valor do pior dia, 22 de dezembro, para cada parede, na latitude $30^{\circ}$ Sul, onde está aproximadamente o município de Estrela/RS. Para as faces Norte esse valor é $179 \mathrm{~W} / \mathrm{m}^{2}$ às $12 \mathrm{~h}$, para as faces Leste é de $715 \mathrm{~W} / \mathrm{m}^{2}$ às $8 \mathrm{~h}$, para as faces Oeste é $715 \mathrm{~W} / \mathrm{m}^{2}$ às $16 \mathrm{~h}$ e para a cobertura é de $1034 \mathrm{~W} / \mathrm{m}^{2}$ às $12 \mathrm{~h}$. $\operatorname{aos} 23^{\circ} \mathrm{C}$.

A temperatura externa foi considerada em $34{ }^{\circ} \mathrm{C}$ e a interna deve chegar

Fluxo térmico total que atravessa o fechamento $(Q)$

$$
\begin{aligned}
& Q=A^{*} q \\
& \mathrm{~A}=\text { área da superfície }
\end{aligned}
$$

A Tabela 2, 3 e 4 apresentam os valores de q, A e Q, para a suíte 1 e 2 e para a sala de jantar.

Tabela 2 - Valores de q, A e Q da Suíte 1

\begin{tabular}{l|l|l|l}
\hline Suíte 1 & $\mathbf{q}\left(\mathbf{W} /\left(\mathbf{m}^{\mathbf{2}} \cdot \mathbf{K}\right)\right)$ & $\left.\mathbf{A} \mathbf{( m}^{\mathbf{2}}\right)$ & $\mathbf{Q}(\mathbf{W})$ \\
\hline Parede vazada - Leste & 46,173 & 4,920 & 227,171 \\
\hline Parede maciça (viga) - Leste & 68,754 & 0,570 & 39,190 \\
\hline Parede vazada - Norte & 31,005 & 9,360 & 290,209 \\
\hline Parede maciço (viga) - Norte & 46,169 & 0,684 & 31,580 \\
\hline Cobertura & 57,023 & 10,800 & 615,850 \\
\hline
\end{tabular}

Fonte: das autoras.

Tabela 3 - Valores de q, A e Q da Suíte 2

\begin{tabular}{l|l|l|l}
\hline Suíte $\mathbf{2}$ & $\mathbf{q} \mathbf{( W / ( \mathbf { m } ^ { 2 } \cdot \mathbf { K } ) )}$ & $\mathbf{A}\left(\mathbf{m}^{\mathbf{2}}\right)$ & $\mathbf{Q} \mathbf{( W )}$ \\
\hline Parede vazada - Leste & 46,173 & 4,920 & 227,171 \\
\hline Parede maciço - Leste & 68,754 & 0,570 & 39,190 \\
\hline Cobertura & 57,023 & 10,800 & 615,850 \\
\hline
\end{tabular}

Fonte: das autoras. 
Tabela 4 - Valores de q, A e Q da Sala de Jantar

\begin{tabular}{l|l|l|l}
\hline Sala de Jantar & $\mathbf{q}\left(\mathbf{W} / \mathbf{m}^{\mathbf{2}} \cdot \mathbf{K}\right) \mathbf{)}$ & $\mathbf{A} \mathbf{( m}^{\mathbf{2}} \mathbf{)}$ & $\mathbf{Q} \mathbf{( W )}$ \\
\hline Viga - Norte & 46,169 & 1,026 & 47,370 \\
\hline Viga - Oeste & 68,754 & 77,330 & 5316,760 \\
\hline Pilar - Norte & 37,821 & 0,754 & 28,517 \\
\hline Pilar - Oeste & 56,323 & 0,754 & 42,467 \\
\hline Cobertura & 57,006 & 20,955 & 1194,570 \\
\hline
\end{tabular}

Fonte: das autoras.

Para o cálculo do fluxo térmico considerou-se apenas as paredes com faces externas e a cobertura dos ambientes analisados, sendo assim desconsiderados os banheiros das suítes e as demais paredes internas.

\subsection{Cálculo Fechamentos Transparentes}

Já nos casos de utilização de vidros, o valor da transmitância térmica (U) é informada pelo fabricante, variando conforme cada material, cor, espessura e camada de ar presentes.

Para fechamentos transparentes, calcula-se:

\section{Fluxo Térmico por Condução (qa)}

$$
q a=U^{*}(t e-t i)
$$

A transmitância térmica do vidro comum de $3 \mathrm{~mm}$ é encontrado no Catálogo de Propriedades Térmicas de Paredes, Coberturas e Vidros (INMETRO, 2013), sendo igual a $\frac{W}{m^{2} * K}$.

\section{Ganho Solar pelo Vidro (qs)}

$q s=F s{ }^{*} I$

$\mathrm{Fs}=$ fator solar determinado pelo fabricante

O fator solar do vidro comum é igual a 0,87 .

\section{Fluxo Térmico (q)}

$$
q=q a+q s
$$

Fluxo térmico total que atravessa o fechamento $(Q)$

$$
Q=A^{*} q
$$

A Tabela 5 apresenta os resultados para os fechamentos transparentes. 
Tabela 5 - Fechamentos transparentes

\begin{tabular}{l|l|l|l|l|l}
\hline & $\mathbf{q a}\left(\mathbf{W} /\left(\mathbf{m}^{\mathbf{2}} \cdot \mathbf{K}\right)\right)$ & $\mathbf{q s}\left(\mathbf{W} /\left(\mathbf{m}^{\mathbf{2}} . \mathbf{K}\right)\right)$ & $\mathbf{q}\left(\mathbf{W} /\left(\mathbf{m}^{\mathbf{2}} . \mathbf{K}\right)\right)$ & $\mathbf{A ~ ( \mathbf { m } ^ { 2 } )}$ & $\mathbf{Q}(\mathbf{W})$ \\
\hline Vidro Suíte 1 - Leste & 62,70 & 622,05 & 684,75 & 2,88 & 1972,08 \\
\hline Vidro Suíte 2 - Leste & 62,70 & 622,05 & 684,75 & 2,88 & 1972,08 \\
\hline $\begin{array}{l}\text { Vidro Sala de Jantar - } \\
\text { Norte }\end{array}$ & 62,70 & 155,73 & 218,43 & 13,26 & 2896,38 \\
\hline $\begin{array}{l}\text { Vidro Sala de Jantar - } \\
\text { Oeste }\end{array}$ & 62,70 & 622,05 & 684,75 & 11,44 & 7833,54 \\
\hline
\end{tabular}

Fonte: das autoras.

\subsection{Cálculo Total}

Fazendo o somatório do fluxo térmico total dos fechamentos opacos e transparentes por ambiente tem se na primeira Suíte: 3176,08 Watts, na segunda Suíte: 2854,29 Watts, e na Sala de Jantar: 17359,61 Watts. Segundo à análise, o valor mais expressivo foi na sala de jantar, devido à grande quantidade de vidro em seu fechamento externo.

Os valores apresentados são apenas dos fechamentos externos, sem contabilizar o fluxo térmico devido à presença de pessoas e equipamentos elétricos.

\section{ANÁLISES E ENSAIOS}

\subsection{Desempenho térmico inicial}

Com os resultados do fluxo térmico total dos ambientes, foram feitos os acréscimos necessários (iluminação, equipamentos e pessoas), além da transformação de Watts para BTU/h (1 Watt é igual a 3,412 BTU/h), para possibilitar o dimensionamento do aparelho de ar condicionado.

Tabela 1 - Eficiência dos ambientes em Watts e BTU/h

\begin{tabular}{l|l|l}
\hline Suíte $\mathbf{1}$ & Suíte $\mathbf{2}$ & Sala de Jantar \\
\hline 2 pessoas $=300 \mathrm{~W}$ & 2 pessoas $=300 \mathrm{~W}$ & 6 pessoas $=900 \mathrm{~W}$ \\
\hline 2 luminárias $=9 \mathrm{~W}$ & 2 luminárias $=9 \mathrm{~W}$ & 3 lâmpadas $=120 \mathrm{~W}$ \\
\hline $1 \mathrm{TV}=90 \mathrm{~W}$ & $1 \mathrm{TV}=90 \mathrm{~W}$ & 1 geladeira $=200 \mathrm{~W}$ \\
\hline 1 lâmpada teto $=40 \mathrm{~W}$ & 1 lâmpada teto $=40 \mathrm{~W}$ & \\
\hline Fluxo térmico $=3176,08 \mathrm{~W}$ & Fluxo térmico $=2854,29 \mathrm{~W}$ & Fluxo térmico $=17359,61 \mathrm{~W}$ \\
\hline Total $=\mathbf{3 6 1 5 , 0 8 ~} \mathbf{W}$ & Total $=\mathbf{3 2 9 3 , 2 9 ~} \mathbf{W}$ & Total $=\mathbf{1 8 5 7 9 , 6 1} \mathbf{~ W}$ \\
\hline $\mathbf{1 2 3 3 4 , 6 5 ~} \mathbf{B T U} / \mathbf{h}$ & $\mathbf{1 1 2 3 6 , 7 1 ~} \mathbf{B T U} / \mathbf{h}$ & $\mathbf{6 3 3 9 3 , 6 2} \mathbf{~ B T U} / \mathbf{h}$ \\
\hline
\end{tabular}

Fonte: das autoras 
Para simular os gastos com energia com o atual ambiente foi feito uma simulação de gastos com o uso de ar condicionados para manter a temperatura interna de $23{ }^{\circ} \mathrm{C}$. A suíte 1 e 2 necessitariam a adoção de um ar condicionado de 12.000 BTU cada, e a sala de jantar iria precisar da instalação de um ar condicionado de 65.000 BTU. Com as potências dos aparelhos determinadas, para saber a quantidade de kW.h utilizado por eles, basta dividir a potência do aparelho por 1000. Sendo assim, o consumo de kW.h dos aparelhos de 12.000 BTU é de 1,2 kW.h, e do aparelho de 65.000 BTU é de 6,5 kW.h.

Nos casos da suítes foi estimado que o tempo de uso do ar condicionado seria de 8 horas por dia, em 21 dias do mês. Já na sala de jantar foi estimado o uso de 6 h por dia em 21 dias por mês. O uso de kW.h da suíte 1/suíte 2 e sala de jantar é respectivamente: 201,6 kW.h e 819 kW.h.

A tarifa da energia elétrica utilizada foi de $\mathrm{R} \$ 0,64 / \mathrm{kWh}$, que é a tarifa residencial amarela $(\mathrm{R} \$ 0,41 / \mathrm{kWh})$ com o acréscimo de 30\% de ICMS e mais $10 \%$ de taxas de iluminação pública, conforme disponível no site da RGE Sul, companhia elétrica que atende o município de Estrela/RS. O gasto mensal da suíte 1 /suíte 2 foi estimado em $R \$ 129,02$ e da sala de jantar foi estimado em $\mathrm{R} \$ 524,16$. Sendo assim, os gastos totais mensais com os equipamentos de ar condicionado dos três ambientes ficaram em $\mathrm{R} \$ 782,20$.

\subsection{Solução proposta}

Tendo em vista os resultados obtidos com os materiais inicialmente utilizados, propõe-se uma substituição de alguns dos mesmos para a adoção de materiais com melhor desempenho térmico, buscando uma eficiência energética desta residência e uma maior economia na conta de energia.

$\mathrm{Na}$ parede, optou-se por manter a estrutura a mesma, apenas foi acrescentado uma camada de $8 \mathrm{~cm}$ de poliestireno estrudado, tanto no bloco vazado $\left(\mathrm{U}=0,371 \mathrm{~W} /\left(\mathrm{m}^{2} . \mathrm{K}\right)\right)$, quanto no bloco maciço de concreto $(\mathrm{U}=0,389$ $\left.\mathrm{W} /\left(\mathrm{m}^{2} \cdot \mathrm{K}\right)\right)$. Todos os vidros externos encontrados na janela da primeira suíte e na sala de jantar, foram substituídos por um conjunto de vidro e breeze na sua parte externa, o vidro é do tipo insulado de controle solar prata de $24 \mathrm{~mm}$, da marca Glassec Viracon, que conta com uma camada de ar entre os vidros, melhorando assim o valor da transmitância térmica $\left(\mathrm{U}=1,48 \mathrm{~W} /\left(\mathrm{m}^{2} \cdot \mathrm{K}\right)\right)$. Na cobertura também se manteve a mesma estrutura, apenas foi modificado a telha de barro para uma telha sanduíche com camada de $5 \mathrm{~cm}$ de espuma rígida de poliuretano, com $1 \mathrm{~cm}$ de telha metálica em cada lado $\left(\mathrm{U}=0,39 \mathrm{~W} /\left(\mathrm{m}^{2} \cdot \mathrm{K}\right)\right)$.

Desta forma, calculou-se novamente o desempenho térmico dos ambientes. Sendo o fluxo térmico total na primeira Suíte: 407,14 Watts, na segunda Suíte: 357,97 Watts, e na Sala de Jantar: 1915,97 Watts. Somando o calor transmitido pelas pessoas que ocupam o ambiente mais os equipamentos elétricos mostrados anteriormente, encontrou-se respectivamente: 846,14 W, 796,97 W e 3135,97 W. Transformando esses valores para BTU/h: 2887,03 
BTU/h, 2719,26 BTU/h e 10699,93 BTU/h. Sendo assim, em ambas as suítes, se o proprietário optar por instalar um condicionador de ar, pode escolher um de 7.000 BTU, que é o menor disponível no mercado, e na sala de jantar pode ser instalado um de 12.000 BTU.

Para simular os novos gastos com energia utilizou-se a mesma tarifa ( $\mathrm{R} \$ 0,64 / \mathrm{kW} . \mathrm{h})$ e o mesmo uso diário de cada equipamento de ar condicionado, chegando no valor de $\mathrm{R} \$ 75,26$ para cada suíte e de $\mathrm{R} \$ 96,77$ para a sala de jantar.

\section{RESULTADOS}

Com a substituição do sistema inicial do projeto para o proposto neste artigo, há grande melhora na eficiência térmica desta residência. Pois a redução do fluxo térmico total foi grande, gerando menos necessidade de possuir algum tipo de ventilação forçada, como o ar condicionado, por exemplo.

O Gráfico 1 faz o comparativo dos gastos com energia elétrica dos 3 equipamentos de ar condicionado, antes das melhorias e após as melhorias.

Gráfico 1 - Gastos mensais com energia

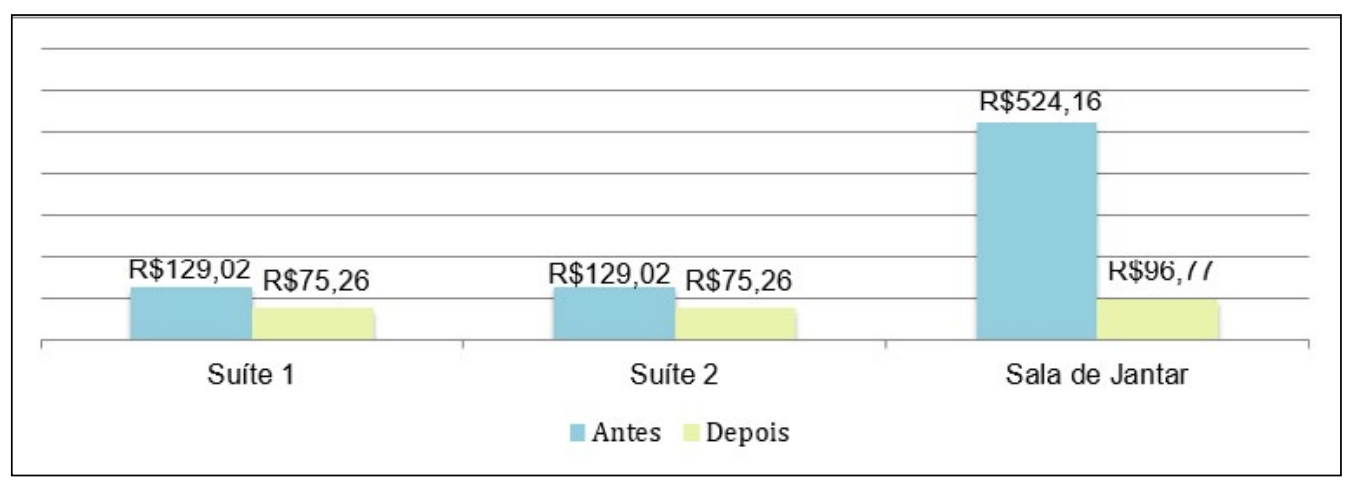

Fonte: das autoras.

A economia total gerada mensalmente pela adoção do segundo conjunto de materiais é de $\mathrm{R} \$ 534,91$, ou seja, $68,38 \%$ da conta total. Em um ano a economia chega a $\mathrm{R} \$ 6418,94$. Mostrando assim, que a utilização de materiais com um melhor desempenho térmico pode fazer muita diferença na quantidade da energia elétrica necessária para refrigerar um ambiente.

\section{REFERÊNCIAS}

ASSOCIAÇÃO BRASILEIRA DE NORMAS TÉCNICAS. NBR15575-1: Edificações habitacionais - Desempenho. Parte 1: Requisitos gerais. Rio de Janeiro: ABNT, 2013. 
ASSOCIAÇÃO BRASILEIRA DE NORMAS TÉCNICAS. Projeto 02:135.07-001/2: Desempenho Térmico de Edificações Parte 2: Métodos de Cálculo da Transmitância Térmica, da Capacidade Térmica, do Atraso Térmico e do Fator Solar de Elementos e Componentes de Edificações. Rio de Janeiro: ABNT, 2003.

FAVOINO, Fabio; JIN, Qian; OVEREND, Mauro.Design and Control Optimisation of Adaptive Insulation Systems for Office Buildings. Part 1: Adaptive Technologies and Simulation Framework. Energy, v. 127, n. 1, p. 301-309, 2017.Disponível em: <http:/ / www.sciencedirect.com/science/article/pii/S0360544217304589>. Acesso em: 11 abr. 2017.

GIVONE, Baruch. Man, ClimateandArchitecture. London:Elsevier, 1981.

GlassecViracon. Vidro Insulado. Disponível em: <http:/ / www.glassecviracon.com. br/produtos/insulado/\#insulado>. Acesso em 22 abr. 2017.

PERALTA, Gizela. Desempenho Térmico de Telhas: Análise de Monitoramento e Normatização Específica. 2006. 131 p. Dissertação (Mestrado em Arquitetura e Urbanismo) - Universidade de São Paulo, São Carlos, 2006. 